\title{
Catarse: memória, história e autoritarismo nas eleições brasileiras de 2018
}

Catharsis: mémoire, histoire et autoritarisme dans les élections brésiliennes de 2018

Catharsis: memory, history and authoritarianism in the 2018 Brazil elections

\section{Guilherme Ribeiro}

\section{(2) OpenEdition}

Journals

\section{Edição electrónica}

URL: http://journals.openedition.org/espacoeconomia/9195

DOI: 10.4000/espacoeconomia.9195

ISSN: 2317-7837

\section{Editora}

Núcleo de Pesquisa Espaço \& Economia

\section{Refêrencia eletrónica}

Guilherme Ribeiro, «Catarse: memória, história e autoritarismo nas eleições brasileiras de 2018 », Espaço e Economia [Online], 16 | 2019, posto online no dia 03 janeiro 2020, consultado o 10 janeiro 2020. URL : http://journals.openedition.org/espacoeconomia/9195 ; DOI : 10.4000/espacoeconomia. 9195

Este documento foi criado de forma automática no dia 10 janeiro 2020.

(c) NUPEE 


\section{Catarse: memória, história e autoritarismo nas eleições brasileiras de 2018}

Catharsis: mémoire, histoire et autoritarisme dans les élections brésiliennes de 2018

Catharsis: memory, history and authoritarianism in the 2018 Brazil elections

\section{Guilherme Ribeiro}

\section{I}

(ca.tar.se)

sf.

3 1. Psi. Sentimento de alívio ao se trazerem à consciência sentimentos, traumas etc. que estavam reprimidos

4 2. Liberação desses sentimentos através de encenação etc.

5 3. Rel. Fil. Na Antiguidade grega, libertação ou purgação do que é estranho à essência ou à natureza de um ser

6 4. Med. Evacuação dos intestinos

$7 \quad$ [F.: Do gr. kátharsis. ${ }^{1}$

\section{II}

8 No primeiro semestre de 1998, ao ingressar no curso de licenciatura em geografia na Faculdade de Formação de Professores da Universidade do Estado do Rio de Janeiro (FFP/UERJ) localizada no município de São Gonçalo, descobri com notável excitação um livro que se tornou minha entrada nas Ciências Humanas: Mozart, a sociologia de um gênio, do alemão Norbert Elias (ELIAS, 1995). Amadeus, a obra-prima do diretor tcheco 
Milos Forman ganhadora de oito Oscars no ano de 1985, já era minha velha companheira em formato VHS desde meados dos anos noventa, mas a retórica e a prosa de Elias ensinaram-me como a sociedade se configura a partir das estruturas de poder e de prestígio e como é difícil colocá-las em xeque. Aprendi também que indivíduos se organizavam em grupos de interesse e que estes vivem em permanente conflito - e isto antes mesmo de conhecer o materialismo histórico e dialético. Talvez por isto o economicismo nunca tenha me convencido. Hoje, tenho plena consciência das razões pelas quais o livro e o filme tanto me atraíram. Queria "vencer na vida" e mudar a sociedade por meio da educação. Debutando nela como ex-aluno de escola pública e morador da periferia da periferia de São Gonçalo, eu, Guilherme da Silva Ribeiro, era o próprio Mozart.

III

9 Ao preparar-me para o vestibular, um programa com ótimas aulas e docentes no canal público TV Cultura tocou-me fundo. Tema: ditadura militar brasileira. Corria o ano de 1997 e, ao olhar tanto para o meu passado familiar quanto para o meu presente à época, lembro-me de chorar envergonhado por causa daquele capítulo da história do meu país. Jovens podem até aprender Matemática, mas ainda não são capazes de entender o alcance da História (acaso alguém conhece algum superdotado neste campo?). São muitos sujeitos, escalas e processos envolvidos, mas, sobretudo, o que lhes falta é a própria lida com o tempo que, em um determinado momento da vida, inevitavelmente obrigará cada indivíduo adulto a encarar o passado com um misto de temor e respeito em busca de autocrítica e de compreensão do presente. Assim, aos dezessete anos, eu estava seguro de que aquele período repleto de atos de violência, tortura e censura cometidos pelo Estado sob a chancela de boa parte da sociedade civil jamais se repetiria. Diria mesmo que nem em meus pesadelos os mais reais isto pareceria plausível.

\section{IV}

Em mesa-redonda na Universidade Federal Rural do Rio de Janeiro em $2018{ }^{2}$ cujo intuito era o de problematizar as consequências do impeachment de Dilma Rousseff idealizado dois anos antes pela professora de Direito da Universidade de São Paulo Janaina Paschoal e perpetrado pelo partido que ocupava a vice-presidência, o Movimento Democrático Brasileiro (MDB) (vide a ótima reportagem de DUAILIBI, 2016), sublinhei o fato de que a ditadura militar havia passado em branco em minha casa. Embora conserve nítida a imagem das lágrimas de minha mãe quando da morte de Tancredo Neves e, poucos anos depois, o comentário raivoso do meu pai sobre a incongruência de Lula querer ser presidente e "não ter letra" (embora meu próprio pai fosse menos letrado que Luiz Inácio da Silva e compartilhasse com ele a mesma condição de migrante nordestino em busca de uma vida melhor no Sudeste), nenhuma palavra havia sido proferida sobre os anos de chumbo. No decorrer da vida escolar, o mesmo "hiato", alimentado, desta vez, pela esquizofrenia de disciplinas como Educação Moral e Cívica e Organização Social e Política Brasileira cursadas aos dez e onze anos de idade em 1990 e 1991 e, posteriormente, pela própria ausência de aulas regulares de História no Ensino Médio da rede pública estadual do Rio de Janeiro entre 1994 e 1996. 
Nos últimos meses, ouvi relatos segundo os quais tudo transcorrera normalmente durante o regime militar. "Sim, fecharam o jornal onde eu trabalhava e ninguém me avisou nada, mas, nos dias seguintes, logo estava empregada. Tirando isto, nunca mais soube nem vi nada de estranho...", disse-me na atmosfera da última eleição presidencial uma simpática octagenária que já votara em Lula e no PT mas que, agora, estava propensa a transferir sua escolha para o candidato do PSL ${ }^{3}$. Outro interlocutor, um sexagenário civil mas que já havia servido ao exército, sempre repetia que "nada acontecia com quem não andava errado...". A repetição da palavra "nada", aqui, revela camadas profundas do imaginário coletivo nacional sobre a ditadura. Interpelar silêncios, resgatar esquecimentos: eis uma das definições possíveis para o campo das Humanidades.

\section{V}

11 Um dos primeiros livros acadêmicos logo no início da graduação foi Rumor de sabres. Tutela militar ou controle civil?, assinado pelo cientista político Jorge Zaverucha. Derivado de tese de doutorado defendida em 1990 nos Estados Unidos e publicado em 1994 no Brasil, ao comparar a transição democrática após regimes militares em três países ele verificou que políticos e sociedade civil tentaram e conseguiram controlar os militares na Espanha; na Argentina, tentou-se, mas sem êxito; e, no Brasil, nem houve esforço nesse sentido. Lida em nossos dias, sua reflexão emerge como profecia não pelo apelo à metafísica ou às informações veiculadas pelo You Tube e WhatsApp, mas graças ao poder de desvendamento histórico e analítico das Humanidades: "Em 1986, cheguei ao Departamento de Ciência Política da Universidade de Chicago convencido de que algo grave estava ocorrendo com a então recente transição democrática brasileira. Em vez de caminharmos para uma democracia consolidada, deixávamos aberta a possibilidade de um retrocesso autoritário. O que hoje parece óbvio era considerado delírio" (ZAVERUCHA, 1994:5). Todavia, em recente entrevista à Folha de São Paulo, o mesmo autor afirma que o candidato do PSL não representa ameaça à democracia e que não descartaria votar nele. Ele também sustenta como traço positivo o fato de o referido candidato ter assegurado que as mudanças serão feitas por meio da lei e da Constituição. "Isso não é discurso de quem é autoritário", complementa (vide FOLHA, 2018). Em plena escalada rumo à eliminação de opositores e de partidos visando o monopólio do poder, Carl Schmitt, um dos principais intelectuais adeptos do nazifascismo, escreve um texto denominado O Führer protege o Direito (cf. KERSHAW, 2010: 348 [2008]). Perguntado sobre os anos antecedentes ao golpe de 1964, o general brasileiro Meira Mattos, militante ativo de todo o processo (e autor de livros sobre geopolítica [MEIRA MATTOS, 1975, 1977]), assegura que "As Forças Armadas sempre fazem os movimentos com espírito de legalidade (...) Sempre se busca a solução menos traumática, mais próxima da legalidade" (MATTOS, 2014:96 [1994]). Eis um dos motivos pelos quais em nossos dias a defesa mais preciosa é a da História e da memória, pois ela não nos deixa olvidar tanto a ascensão do nazismo ao poder por meio de eleições livres quanto a evidência de que os militares brasileiros legalizaram a ditadura ${ }^{4}$. Hoje, 28 de outubro de 2018, o Brasil está a poucas horas de sagrar seu novo presidente. 


\section{VI}

12 Aos dezessete anos, uma das várias e emblemáticas fotografias reunidas pelo historiador marxista britânico Eric Hobsbawm em Era dos Extremos: o breve século XX meu livro de cabeceira durante a graduação - fixou-se em minha mente com tamanha intensidade que nada me fará apagá-la: uma multidão de soldados enfileirados, todos uniformizados, em um comício de Adolf Hitler em Nuremberg. O instantâneo foi retirado de algum lugar alto de modo que aparecesse o máximo de recrutas. Defronte ao palco porém bem atrás da imensidão de fileiras estava o fotógrafo (oficial do III Reich, muito provavelmente), cujo ângulo engendrou uma imagem como se os soldados formassem um mar de capacetes tão indistinguíveis quanto indestrutíveis. Ao fundo do palanque e hasteadas a uma altura como se fossem imponentes edifícios, três faixas ostentavam a suástica. À esquerda da foto, suficientemente destacada, a águia, cujos atributos enquadravam-se nos valores de superioridade do National-Sozialistische Deutsch Arbeiter Partei (HOBSBAWM, 1995 [1994]). Dez anos mais tarde, a história se encarnaria diante de meus olhos em uma ocasião tão única quanto inacreditável. Em um evento para jovens estudantes universitários de História na pequena cidade de Cabo Frio onde lecionava, uma mão simultaneamente resistente e trêmula endereçou-me a seguinte dedicatória: "Ao querido Guilherme, por um mundo bom, fraterno e sem preconceitos". Seu nome: Aleksander Henryk Lars. Sua geografia: ter vindo parar no Brasil. Sua chance: ter sobrevivido a Auschwitz. Sim: ter me tornado professor de Humanidades fez com que a vida me ofertasse como presente assistir à sua palestra - e jantar com ele. Grandeza exemplar: o passado desumano não o tornou um tirano (LARS, 2006 [2000]).

\section{VII}

Corria o ano de 2016 e, durante um final de semana em Petrópolis (antiga cidade imperial situada na região Serrana do Estado do Rio de Janeiro), presenciei uma pequena, mas barulhenta, manifestação contra o Partido dos Trabalhadores e a presidenta Dilma Rousseff. Em uma democracia, tal ato não pode senão ser considerado legítimo, quanto mais pelo fato de que o país ainda se encontrava dividido por causa do pleito que derrotou Aécio Neves (PSDB) por pequena margem de votos dois anos antes. Entretanto, chamou-me atenção a virulência do vocabulário escolhido e amplificado ruas afora por meio de um carro de som. Para dizer o mínimo, faltou urbanidade aos participantes. Dois anos mais tarde, revoltado pelo assassinato a tiros da vereadora do PSOL Marielle Franco, eu também exerceria o direito de ir às ruas. Negra, bissexual, oriunda da favela e politicamente de esquerda, assustava-me a frieza de parte considerável da sociedade civil diante de tão brutal acontecimento e que, em muitos aspectos, representa um dos capítulos mais importantes da história brasileira pósredemocratização. Todavia, eu não supunha que tamanha indiferença encontraria a mais sórdida correspondência sete meses depois, quando dois cidadãos destruiriam uma placa de rua confeccionada com o nome da vereadora e colocada em uma das esquinas da Praça Floriano Peixoto no centro do Rio. Na placa, lia-se Rua Marielle Franco. 1979-2018. Vereadora, defensora dos Direitos Humanos e das minorias, covardemente assassinada no dia 14 de março de 2018. Era uma maneira não-oficial de seus eleitores de homenageá-la, pois não houve projeto de lei na Câmara Municipal a respeito. Porém, tal destruição não aconteceu em uma ocasião qualquer, mas em meio a um ato político em 
pleno ar livre. Eu precisaria da força de espírito de Primo Levi para narrar a reação dos presentes ${ }^{5}$ (LEVI, 1988 [1947]). Conclusão para futuros historiadores que quiserem entender o Brasil de hoje: aqueles mesmos cidadãos atendem pelos nomes de Daniel Silveira e Rodrigo Amorim e foram eleitos para os cargos de deputado federal e estadual pelo Rio de Janeiro com 31.789 mil votos e 140.666 mil votos, respectivamente. Eles integram o mesmo partido do mais novo presidente da República. Outro cidadão a também subir no palanque daquele ato chama-se Wilson Witzel, governador eleito do Estado do Rio de Janeiro com quase cinco milhões de votos. O lugar onde tal comício ocorreu denomina-se Petrópolis.

\section{VIII}

14 Episódios relatando ofensas verbais, agressões físicas, queima de livros em bibliotecas públicas de universidades e, mesmo, um homicídio na Bahia, foram amplamente noticiados. Imediatamente após o término do segundo turno, um dos meus familiares foi agredido verbalmente no bairro do Leblon por um partidário do candidato eleito simplesmente por portar um botton do candidato de esquerda que acabara de ser derrotado. Tal exemplo sintetiza não apenas o modus operandi de boa parte da elite e da classe média nacionais, mas a adesão maciça e irrestrita de homens e mulheres dos mais variados estratos sociais a um programa racista, discriminatório, violento. A vontade transformada em ação não apenas de calar, mas de abolir, a diferença - de opinião política, credo religioso, cor da pele, gênero sexual, lugar de origem. Fazer prevalecer, pela força cega da maioria, um único modo de pensar, agir, viver. Milhões de pessoas tomando um homem por um mito. Aqui, nunca uma palavra evocada foi capaz de expressar com tamanha perfeição as características mais horrendas da coletividade social ${ }^{6}$. Mito significa estar fora da história mas, ao mesmo tempo, supostamente deter poderes para nela intervir; embaralhar infantilmente realidade e imaginação; perder a noção de humanidade ao clamar por um super-homem apto a solucionar tudo aquilo que soa como "problema". o mito é um clamor delirante em nome da eliminação do outro e, se porventura a tragédia começar a despontar no horizonte da morte e o tempo histórico exibir sua face irrevogável, a responsabilidade sempre poderá encontrar a desculpa de que nunca ninguém imaginou que as coisas aconteceriam de tal forma ${ }^{7}$. No Brasil de Bolsonaro, na Alemanha de Hitler, nos Estados Unidos de Trump ou em qualquer país do mundo, o mito, tal como descrito acima, é o álibi perfeito do autoritarismo.

\section{IX}

Estamos em meados de dezembro de 2018 e, embora o presidente eleito ainda não tenha assumido, as denúncias envolvendo ele e sua família - inclusive a esposa - já ocupavam os noticiários. Convocado pela Justiça a prestar depoimento sobre movimentações bancárias incompatíveis com seus rendimentos (21 mil reais mensais para 1,2 milhões de reais anuais), além de sua participação como laranja da Família Bolsonaro, Fabrício Queiroz, policial militar, ex-assessor, ex-segurança e ex-motorista de Flávio Bolsonaro (eleito senador pelo Rio de Janeiro com 4.380.418 votos), alegou problemas de saúde e não compareceu ao Ministério Público do Rio de Janeiro. Nos vários grupos de Whatsapp que fizeram campanha diuturna para os Bolsonaro, reinava 
um silêncio sepulcral. Ao questioná-los sobre o caso, as reações variaram da indiferença aos xingamentos. Perguntei aos meus interlocutores a respeito da ética e da moral inabaláveis que eles próprios e a Família Bolsonaro tomaram como bandeira e que, agora, diante desse clã às voltas com a Justiça, gostaria de saber se eles não se sentiam responsáveis por suas escolhas políticas. Uns alegaram que era preciso "deixá-los [os Bolsonaro] trabalhar", enquanto outros sustentaram que o grupo decidiu não mais tratar de política. Um terceiro disse que a eleição já tinha acabado. Um quarto amigo escreveu que só conversaria comigo após o final do mandato de Jair Bolsonaro mas que, independentemente de quem fosse, "bandido tem que ser preso". O outro saiu do grupo. Eu mesmo retirei-me de um. Em todos os casos, um traço comum emerge como sintoma: o empenho, o ímpeto, o engajamento pela política e pelo país (por meio de "memes", vídeos disparatados e fake news, ressalte-se) simplesmente desapareceram. Eu já esperava que isto fosse acontecer, mas, confesso, não com tanta rapidez. A indiferença face à história e a desilusão diante da política há tempos marcam nossa formação social. Reverter esta situação passa, certamente, pela preservação e pela ampliação das Humanidades - e não o oposto, tal como defende a Escola Sem Partido e, também, a Família Bolsonaro.

\section{$X$}

Em uma sociedade democrática, a liberdade de expressão assume papel decisivo. Respeitar e conviver com o outro exige responsabilidade e passa, necessariamente, pela aceitação a diferentes visões sobre a vida social (TODOROV, 2010 [2008]). Por essa razão é que o Estado Moderno se tornou laico, pois, ao representar a todos, ele não poderia professar o credo de ninguém. Igualmente, a liberdade de culto se inscreve nesse contexto ao garantir o não-cerceamento religioso e, por conseguinte, sua pluralidade. Infelizmente, no Brasil da virada do século XX para o século XXI o Protestantismo veio fortalecer os preconceitos tradicionais do conservadorismo religioso, cujas origens nos remetem ao suporte da Igreja Católica ao regime escravocrata da conquista ao fim do Império até a Marcha da Família com Deus pela Liberdade em 1964. Se a promessa de redenção econômica impulsionada pela teologia da prosperidade deve ser aceita como um dos motivos a explicar - majoritariamente entre as camadas populares das periferias - o forte avanço pentecostal nas últimas décadas, o tema dos valores morais não pode ser negligenciado. Tolerância aos pares, intolerância aos outros: eis a fórmula a sintetizar a questão. Através das redes sociais e dos cultos transmitidos on line para milhões de fiéis, o apoio maciço de líderes evangélicos de reconhecida influência nacional a Jair Bolsonaro desnudou sem pudor algum a constatação segundo a qual o casamento entre política e religião é apenas a face mais recente da tragédia históricosocial brasileira, uma espécie de renovação de nossos estigmas e de nossos preconceitos em seu estado mais profundo. De qualquer forma, ninguém sairá impune dessa eleição.

\section{$\mathrm{XI}$}

17 Ao nos interrogarmos sobre quais têm sido os efeitos de quatro séculos de escravidão e de duas ditaduras (Vargas e os anos 1964-1985) tanto sobre o território quanto sobre a mentalidade nacionais, a resposta é tão importante quanto a pergunta, pois parece impossível entender indivíduos, partidos, classes sociais, mídia e poder judiciário fora 
do escravismo e do autoritarismo. No Brasil, a pobreza urbana tem cor e geografia: negros e negras nas periferias e favelas. Igualmente, contradições, hierarquias, preconceitos e resolução de desigualdades têm nome: violência. Não é mera coincidência, portanto, a abundância de discursos minimizando tanto o racismo quanto a ditadura - e, evidentemente, incriminando tudo o que diz respeito ao espectro político de esquerda. Em um país com baixas taxas de escolaridade e com uma elite burocraticamente diplomada porém pouco letrada, a defesa da história, das minorias e, consequentemente, do próprio regime democrático, torna-se exceção à regra. Vinte $\mathrm{e}$ quatro anos após o fim da ditadura, um ex-capitão do Exército é eleito com o voto de 57.797.847 milhões de pessoas. A impressão de que o país anda para trás não é, logo, inexata. Eis o valor da questão acima esboçada, pois, no imaginário da sociedade brasileira, escravidão e autoritarismo ainda ocuparão lugar central por muito tempo. São estruturas poderosas que forjaram e continuarão forjando a compreensão que o brasileiro tem de si mesmo e do seu país (vide SOUZA, 2017). Se quisermos estudar a fundo as razões da derrota da esquerda após quatro vitórias presidenciais seguidas, cabe ao pensamento crítico situá-las no cerne de suas preocupações. Em nosso entendimento, a vitória de Bolsonaro está longe de ser exceção; muito pelo contrário, ela trouxe à tona as características estruturais recorrentes de nossa história.

\section{BIBLIOGRAFIA}

AGAMBEN, Giorgio. Estado de exceção. Tradução de Iraci D. Poleti. Campinas: Boitempo (2004 [2003]).

BENJAMIN, Walter. Sobre o conceito de história. Tradução de Sérgio Paulo Rouanet. In: BENJAMIN, Walter. Magia e técnica, arte e política. Obras escolhidas I. São Paulo: Brasiliense (1994 [1940]).

CHAUÍ, Marilena. Brasil: mito fundador e sociedade autoritária. São Paulo: Perseu Abramo (2000).

DUAILIBI, Julia. A acusadora. Revista Piaui, edição 122, novembro (2016).

ELIAS, Norbert. Mozart: Sociologia de um gênio. Tradução de Sergio Góes de Paula. Rio de Janeiro: Jorge Zahar (1995).

FOLHA de S. Paulo, Bolsonaro não é o vilão da eleição, diz cientista político. Entrevista de $2^{\mathrm{a}}$, 9 de setembro (2018). Disponível em (https://www1.folha.uol.com.br/poder/2018/09/bolsonaro-naoe-o-vilao-da-eleicao-diz-cientista-politico.shtml). Acesso em 28.10.2018.

HOBSBAWM, Eric. Era dos Extremos: o breve século XX: 1914-1991. Tradução: Marcos Santarrita. São Paulo: Companhia das Letras (1995 [1994]).

KERSHAW, Ian. Hitler. Tradução: Pedro Maia Soares. São Paulo: Companhia das Letras (2010 [2008]).

LARS, Aleksander Henryk (com Tova Sender). 0 sobrevivente. $6^{\text {a }}$ ed. Rio de Janeiro: Record (2006 [2000]). 
LEVI, Primo. É Isto um Homem? Tradução de Luigi Del Re. Rio de Janeiro: Rocco (1988 [1947]).

LÖWY, Michael. Walter Benjamin: aviso de incêndio. Uma leitura das teses Sobre o conceito de história. Tradução de Wanda Nogueira Caldeira Brant. São Paulo: Boitempo (2005 [2001]).

MEIRA MATTOS, Carlos de. Depoimento. In: D’ARAÚJO, Maria Celina, SOARES, Gláucio Ary Dillon, CASTRO, Celso (orgs.). Visões do golpe. Doze depoimentos de oficiais que articularam o golpe militar de 1964. Rio de Janeiro: Nova Fronteira (2014 [1994]).

MEIRA MATTOS, Carlos de. A Geopolítica e as Projeções do Poder. Rio de Janeiro: José Olympio (1977). MEIRA MATTOS, Carlos de. Brasil: Geopolítica e Destino. Rio de Janeiro: José Olympio (1975).

OLIVEIRA, Francisco de. Do dualismo ao ornitorrinco. Entrevista com Marcelo S. Ridenti e Flávio da S. Mendes. Caderno CRH, Salvador, v.25, 66, set./dez (2012).

OLIVEIRA, Francisco de. A dominação globalizada: estrutura e dinâmica da dominação burguesa no Brasil. In: BASUALDO, Eduardo M.; ARCEO, Enrique. Neoliberalismo y sectores dominantes. Tendencias globales y experiencias nacionales. Buenos Aires: Consejo Latinoamericano de Ciencias Sociales (2006a).

OLIVEIRA, Francisco de. 0 momento Lênin. Novos Estudos, jul, 75 (2006).

OLIVEIRA, Francisco de. O Estado e a exceção ou o Estado de exceção? Revista Brasileira de Estudos Urbanos e Regionais, vol. 5, n.1, mai (2003).

SOUZA, Jessé. A elite do atraso. Da escravidão à Lava Jato. Rio de Janeiro: Leya (2017).

TODOROV, Tzvetan. 0 medo dos bárbaros. Para além do choque das civilizações. Tradução de Guilherme João de Freitas Teixeira. Petrópolis: Vozes (2010 [2008]).

ZAVERUCHA, Jorge. Rumor de Sabres: tutela civil ou controle militar? São Paulo: Ática (1994).

\section{NOTAS}

1. Cf. dicionário eletrônico Aulete, disponível em http://www.aulete.com.br/catarse . Pela interlocução sobre a política brasileira e pelo estímulo a publicar esse texto, agradeço aos colegas Pablo Ibañez (UFRRJ), Leandro Dias de Oliveira (UFRRJ) e Floriano Godinho de Oliveira (UERJ). Dedico esse ensaio aos meus alunos da periferia do curso de Geografia da UFRRJ.

2. Tratou-se do módulo denominado A geografia do golpe no âmbito do curso de extensão "O golpe de 2016 e o futuro da democracia no Brasil", promovido pela Universidade Federal Rural do Rio de Janeiro em 22 de maio de 2018.

3. A quem interessar possa, encontramos nos artigos de Francisco de Oliveira material excelente para uma autocrítica necessária - porém ainda a ser reconhecida - por boa parte da esquerda brasileira (OLIVEIRA, 2003, 2006, 2006a, 2012).

4. Quando exceção e regra tornam-se indiscerníveis, vide a reflexão de Agamben (AGAMBEN, 2004 [2003]).

5. A consultar o site https://noticias.uol.com.br/politica/eleicoes/2018/noticias/2018/10/08/ witzel-participou-de-ato-em-que-placa-destruida-de-marielle-foi-exibida.htm . Acesso em 30.10.2018

6. Vide, a propósito, a bela mobilização desse conceito em Brasil: mito fundador e sociedade autoritária (CHAUÍ, 2000).

7. Inspiro-me aqui no influente Sobre o conceito de história de Walter Benjamin (1994 [1940]), assim como em sua interpretação proposta por Löwy (LÖWY [2005/2001]). 


\section{RESUMOS}

Redigido entre vinte e oito de outubro (data do segundo turno das eleições presidenciais) e vinte de dezembro de 2018, o ensaio em tela adota uma estratégia narrativa que permite ao autor mobilizar memórias autobiográficas relacionadas à ditadura militar brasileira visando compreender as razões histórico-sociais que levaram à vitória presidencial de Jair Bolsonaro. Simultaneamente, os argumentos arrolados visam sublinhar a relevância da democracia, da liberdade de expressão e das Humanidades no interior de uma sociedade estruturalmente atravessada pela escravidão e pelo autoritarismo e cujos efeitos perduram fortemente até os dias atuais.

Rédigé entre le 28 octobre (date du deuxième tour des élections) et le 28 décembre de 2018 , cet essai adopte une stratégie narrative qui permet à l'auteur de mobiliser quelques mémoires autobiographiques liées à la dictature militaire brésilienne afin de comprendre les raisons historico-sociaux de la victoire présidentielle de Jair Bolsonaro. Au même temps, les arguments développés visent à souligner l'importance de la démocratie, de la liberté d'expression et des Humanités à l'intérieure d'une société structurellement traversée par l'esclavage et par l'autoritarisme, et dont les effets sont fortement subis jusqu'à nos jours.

Written between on 28th October ( $2^{\text {nd }}$ round of the elections) and on 28th December 2018, in this text I adopt a narrative strategy which allows me to mobilize some autobiographical memories related to the military dictatorship in order to understand the historical and social reasons that explain why Jair Bolsonaro won the presidential election. At the same time, my arguments underline the relevance of democracy, free expression and Humanities in a society structured by slavery and by authoritarianism, and whose effects are strongly present nowadays.

\section{ÍNDICE}

Palavras-chave: catarse, autoritarismo, ditadura militar, eleições 2018, Brasil.

Keywords: catharsis, authoritarianism, military dictatorship, 2018 elections, Brazil.

Mots-clés: catharsis, autoritarisme, dictature militaire, éléctions 2018, Brésil.

\section{AUTOR}

\section{GUILHERME RIBEIRO}

Professor Associado II da Graduação e do Programa de Pós-Graduação em Geografia da Universidade Federal Rural do Rio de Janeiro (UFRRJ). Email: geofilos@msn.com ou lapehge@gmail.com 